\title{
Action Research on Integrating Ideological and Political Education into "Short Video Creation" Course in Colleges
}

\author{
Ying Zhao ${ }^{1, *}$, Xiaomei $\mathrm{Gao}^{2}$
}

\author{
${ }^{1}$ Shanghai Technical Institute of Electronics Information \\ ${ }^{2}$ Shanghai Technical Institute of Electronics Information \\ *Corresponding author. Email: xyyxyy021@163.com
}

\begin{abstract}
The arrival of $5 \mathrm{G}$ era will soon lead to a full-scale outbreak of short videos, which will bring more demand for short video, colleges should bear the responsibility of cultivating short video production talents and output short video works with real communication power taking short video creation, the core course of film and television animation major, as the research object, the fundamental task of cultivating people by virtue is fulfilled. To study the effective integration method of ideological and political education and the professional course of "Short Video Creation", train students to establish firm socialist core values, undertake the mission and responsibility as a media worker, and convey beautiful and valuable content with the professional attitude of communicators export high-quality talents for the audio-visual industry, present high-quality short video content with more valuable identification, emotional resonance and rich connotation for the broad masses of the people, so as to meet the spiritual needs of the people.
\end{abstract}

Keywords: Short Video, Ideological Education, The core values of Chinese socialism.

\section{INTRODUCTION}

Since 2013, short video products have gained explosive growth with the characteristics of fragmented communication and socialization, and short video has been sought after by more and more users. In 2020, under the catalysis of COVID-19 epidemic, more value of short videos will be tapped with the empowerment of big data, artificial intelligence, virtual reality, 5G and other new technologies, short video as an information carrier, will enter a new period of deep development. On June 2, 2021, China Network Audiovisual Program Service Association officially released the Research Report of 《2021 China Network Audio Visual Development Research Report》. According to the Report, as of December 2020, the scale of network audio-visual users in China reached 944 million, among which the scale of short video users reached 873 million. From June to December 2020, there were 49.15 million new netizens in China. Among them, 25.2\% of the new netizens are exposed to the Internet because they use audio-visual applications on the Internet, and short video is the most attractive to netizens. $20.4 \%$ of the new netizens use short video applications when they surf the internet for the first time, ranking second only to instant messaging. ${ }^{[1]}$ According to 《2020 Tik Tok data report》 , as of August 2020, the number of daily active users in Tik Tok exceeded 600 million, and as of December 2020, the average daily video search times in Tik Tok exceeded 400 million with the characteristics of fragmentation, high dissemination and low threshold, short video products have surpassed long video and become the mainstream content form in the market. ${ }^{[2]}$

\section{RESEARCH STATUS OF SHORT VIDEO AT HOME AND ABROAD}

Gibbs and Colin were the first foreign researchers to study short video. They introduced short video applications in the article Short-form may be long-tail for mobile video, and predicted that mobile short video applications would become a battleground in the media market. ${ }^{[3]}$ Foreign academic research in the field of short video is mostly client-oriented research, and explores the influence of short video from the development of inter-industry interoperability.

At present, the domestic academic research on short video mainly focuses on the rise and development of 
short video, its propagation mode, its commercial price and its content production. Starting from 2018, more and more researchers began to pay attention to the attempt of short videos to promote core values and main themes, Yu Shu ${ }^{[4]}$ pointed out that," the mainstream media should seize the seal of short video and make positive publicity, so that the main theme is louder and the core values are more widely spread." The articles of Jinling Zhang ${ }^{[5]}$ also affirmed the attempt and innovation of short videos in promoting core values and main melody. Yuting Luo and Yongtu $\mathrm{Li}^{[6]}$ of Wuhan University put forward the main theme of actively promoting society, giving full play to the leading role of advanced models and using Tik Tok to do well in ideological and political education for college students has been widely recognized. These explorations are the viewpoint studies of short videos after a series of rectifications, and none of them go deep into the formation of specific creative thinking and the specific implementation methods of content creation.

\section{COLLEGE STUDENTS PARTICIPATE IN THE PRODUCTION OF SHORT VIDEO CONTENT}

Short video products are very popular among young people, especially short video with TikTok, which has become the mainstream social platform for college students to socialize, obtain information resources and express their ideas. At the beginning of the listing, TikTok short videos are positioned as young people under the demand of fragmented entertainment, attracting young people who pay attention to fashion trends in first-and second-tier cities. According to 2020 Tik Tok University Student Data Report, as of December 31,2020 , the number of university students in Tik Tok has exceeded 26 million, accounting for nearly $80 \%$ of the total number of university students in China. In 2020, the total number of videos released by university students in Tik Tok exceeded 311 trillion, with 118.4 billion likes and 2.7 billion shares. On the Tik Tok, there are constantly emerging "college students'talents" with diverse fields and solid contentyouth, inspirational and positive energy contents such as "military training", "beginning of school" and "graduation" have attracted much attention from users among them, "Dormitory Life" video truly reflects the "dormitory culture" of college students, which is lively and grounded, and is most popular among users in Tik Tok, with related videos playing 8.6 billion times ${ }^{[7]}$.College students have a relatively high education level, are keen on new things and have a strong desire for self-expression, which has become the main force in the production of TikTok short videoshowever, college students are in the critical period of shaping and stabilizing the "Three Views", and conveying the correct values will inevitably arouse the audience's empathy. The integration and symbiosis of short videos and youth values is necessary to meet the growing needs of young people for a better life, and it is also the proper meaning of the sustained and healthy development of short videos in the all-media era.

To sum up, as a new media form, short video has not developed for a long time. Foreign scholars and scholars mostly focus on the research of short video application platform and user groups, but there is no systematic research on the content creation of short video itself. With the attention paid by the national propaganda department to short videos, short videos try more and more on core values, main melody, national image and so on, and gradually become the new direction of short videos in the future. However, how to cultivate creative thinking with socialist core values from the school teaching stage and in the process of professional study, and how to make the main melody content with communication power are urgent problems to be solved. It is also the research direction of this paper.

\section{THE PURPOSE OF INTEGRATING IDEOLOGICAL AND POLITICAL EDUCATION INTO THE COURSE OF "SHORT VIDEO CREATION"}

First, it provides theoretical guidance for cultivating students' socialist core values. For the first time, the 18th National Congress of the Communist Party of China made it clear that cultivating people by virtue is the fundamental task of education, only by grasping its essential connotation can we truly answer the fundamental question of who to train, how to train and for whom, cultivate and practice socialist core values. It is a new requirement and a new task given to the education industry in the new period, and it is also the only way to cultivate people in the new period deepen the reform of ideological and political education in professional courses, integrate the education of socialist core values into the professional course of Short Video creation in higher vocational colleges, form creative thinking based on correct values, and then create and output short video works under the guidance of creative thinking. This process is an effective way to cultivate and practice the socialist core values of vocational college students.

Second, find the effective path of ideological and political education in vocational education curriculum. Adhere to the goal of improving professional skills and professional quality with the guidance of socialist core values, design teaching content according to specialty and curriculum characteristics, and adopt special embedded, invisible penetrating, finishing touch, element combination and other ways to integrate ideological and political elements with professional knowledge. Reasonably arrange the teaching process and curriculum structure, and form an exemplary overall teaching design of "course ideological and political education". 
Third, study the typical cases of short videos, concise and summarize the values and logical laws behind their contents, and apply them to the creation of short videos of main melody. It provides a new way of thinking and method for the production and creation of short videos, trains short video producers with core values, and produces the main theme short videos with communication power.

\section{THE NECESSITY AND FEASIBILITY OF INTEGRATING IDEOLOGICAL AND POLITICAL EDUCATION INTO THE COURSE OF "SHORT VIDEO CREATION"}

For a long time, vocational college students generally do not care about ideology and politics, and have strong self-awareness. Moreover, the traditional ideological and political education is not very effective, and students are not interested in the teaching of ideological and political courses, which directly leads to students' lack of professional ethics, weak sense of social responsibility, deviation of outlook on life and values, and poor post adaptability. Taking the creation of popular short videos as the breakthrough point, it is necessary to carry out ideological and political education for students in the teaching of professional knowledge by adopting methods that are more interesting and recognized by higher vocational students.

The most important characteristics of students majoring in art in higher vocational colleges are strong perceptual knowledge, strong interest in learning professional courses, and strong ability of practice and application. Make use of the practical participation mode of short video production that students are interested in, and deeply integrate ideological and political education with professional courses to help students deeply understand and establish socialist core values. Form a director's thinking with insight into good things, warm spots and emotional empowerment, combine the popular factors and creative techniques of short videos, and practice the socialist core values through the practical application of short video creation. Therefore, it is feasible to integrate ideological and political education into the course of "Short Video Creation".

\section{IMPLEMENTATION OF IDEOLOGICAL AND POLITICAL COURSE OF "SHORT VIDEO CREATION"}

"Short Video Creation" is a course that combines artistry and technicality. The creative thought plays a decisive role from the previous topic selection and script creation, to the actual shooting, and then to the later editing and synthesis, the primary task of curriculum design is to dig deep into the ideological and political elements in the course teaching content, while imparting knowledge and skills, we will integrate the education of socialist core values into the design of professional courses, enhance our own ideological understanding in the process of learning professional knowledge, form a director's thinking with core values, and become an influential short video producer.

\subsection{Mining and Instructional Design of Ideological and Political Elements}

According to the process of film and television creation, ideological and political education is embedded from various angles and dimensions from the stages of topic selection, script creation, role shaping, material shooting and editing, and practical teaching plans are designed and formulated. The curriculum always focuses on the theme of promoting socialist core values. Use various teaching methods to integrate ideological and political education based on socialist core values at different stages of the curriculum.

In the stage of topic selection, this paper studies how to help students establish correct three views to form correct thinking of topic selection, invisible penetration of the leading and soul role of socialist core values in the knowledge points of positive high awakening topics, grasping hot spots from three levels of the world, the country and the individual, and selecting high-value content subjects at the stage of script creation. In the theoretical knowledge of drama principle and drama structure, the embedded teaching of strengthening ideals and beliefs, creating life value, carrying forward Chinese virtues, fearing life, and giving thanks and rewarding can guide students to get inspiration for script creation through attention, care and observation. In the role-building stage, to study how to cultivate students' insight into the beautiful human nature and shape vivid roles. Through the case analysis in the explanation of knowledge points of different types of roles, the typical cases showing excellent characters' character with friendly, dedicated, honest, law-abiding and selfconfident characters are analyzed with the finishing touch. Students are influenced by these excellent characters and infected by ingenuity. In the production stage of video shooting and editing, this paper studies how to cultivate students' ability to grasp warm spots and emotional empowerment to achieve high value and high awakening of works. Through the combination of audio-visual impact and emotional awakening brought by audio-visual processing techniques in the learning process of software editing technology, at the same time, it emphasizes various norms in the practical training operation process, establishes professional dedication and exercises professional quality. 


\subsection{The Concrete Implementation of Integrating Ideological and Political Elements into Curriculum Content}

\subsubsection{Topic Selection Stage}

In the topic selection stage, help students establish correct three views. The topic selection based on correct three views is easier to be accepted by the audience, and the works need to spread and guide positive energy thoughts. Give full play to the leading and soul role of socialist core values, think from the three levels of the world, the country and the individual, and select highvalue content subjects world level: closely following the pulse of the times, focus on the global changes. For example, the African high-speed rail aided by China's "The Belt and Road Initiative" project shows the impact of Chinese standards, Chinese technology and Chinese equipment on the world, and shows China's economic strength. At the national level: pay attention to the development of the country, carry forward the Chinese spirit and establish national self-confidence. Feel the vigorous development of the country. Experience the close integration of personal development and national development. Such as the first application of quantum communication transmission in China, the global leading of China's 5G communication technology, the successful networking of Beidou-3 navigation satellite, and China's outstanding performance in the global antiepidemic in COVID-19In this kind of topic selection, guide students to pay attention to the mainstream media account content in short video platform. Learn about the country's breakthroughs in various fields, feel the vigorous development of the country, and experience the close integration of personal development and national development. Personal level: The changes in lifestyle and habits of sports, fitness and leisure travel in daily life show that people live in a new era with increasing pride and happiness. Through the excavation and thinking based on these three levels of themes, students' emotional identity can be strengthened while cultivating their thinking on topic selection, which can generate strong resonance, form broad consensus, build the foundation of faith, cultivate students' feelings of home and country, stimulate patriotic enthusiasm and set up their ambition to serve the country.

\subsubsection{Script Creation Stage}

In the stage of script creation, starting from the classic theory, students first learn the classic script patterns such as Franz pyramid structure, Sid Field's three-act structure and Hegel's "conflict law" structure, and then analyze the drama structure of classic short video cases, such as "Late Night Lighting" series short films, on a dark road. A student is riding a bicycle in front, the driver behind him turns on the headlights, and a beam of light illuminates the student's road. Suddenly, the student stopped and turned backward, bowed deeply to the driver behind him, and then moved on. Based on the three-act structure analysis, a kind behavior between people in the video is reasonably connected between the two scenes of construction and confrontation. It makes the story structure quickly complete the change of starting, inheriting, turning and combining. This unexpected and reasonable move aroused the audience's inner feelings. At the same time, it teaches students that script creation starts from a bit of happiness in life, grows constantly in a clever and reasonable plot turning point, has a complete narrative structure and dramatic changes in the plot, it can attract the audience to put in deep emotions, stimulate the audience's emotional reaction and finally produce emotional resonance. The inspiration of script creation should come from reality and real life experience, train students to experience life with heart, accumulate life materials and turn them into dramatic elements, so as to guide students to pay attention to the people's livelihood, the development of the country and feel the people and things around them. Discover harmony, fairness and civilization in life, and grasp the spiritual essence of socialist core values.

\subsubsection{Role-building Stage}

In the role-building stage of script creation, various types of cases of short video platform are summarized. Taking daily life and the working conditions of people in different industries as examples, students are guided to show the positive change process of their roles overcoming their internal defects or gaining new life in the struggle process of external environmental obstacles. Cultivate students' insight into beautiful human nature. Excavate the character's self-transcendence and selfachievement; Show the excellent character of friendliness, dedication and honesty. For example, the role of love should be to break through the inherent prejudice that men are superior to women and realize the equal relationship between spouses; Children's rolebuilding should show their loveliness from the innocent point of view, we can't show jokes caused by the difference between children's ignorance and adults' cognition. The role-building of fashionable youth should not focus on their high-value appearance, but should show inspirational stories of working harder than those around them under excellent external conditions. For the role-building of street performers who choose different lifestyles, should present the life attitude of selfconfidence and satisfaction after the choice of life. When portraying the characters of the bottom of society, we should not only show the hardships behind the industry, but also highlight their attitude of actively fighting hard, living hard and living seriously in the face of external environmental obstacles. 


\subsubsection{Shooting and Editing Stage}

In the production stage of video shooting and editing, the audio-visual impact brought by the combination of theme pictures and music is combined with software technology to present the high value and high awakening of video. High value: stunning and cool videos are more popular with young friends, and at the same time can stimulate the creative desire of young students. Amazing and cool videos are not only displayed on the screen, at the same time, it also includes different forms of expression and special creative methods. For example, in the same scene, the contrast between the poor gray picture before the reform and opening up and the colorful picture changing with each passing day shows the remarkable achievements made in the development of New China in the past 40 years. Through the software editing technology, we can realize the production and study of dynamic data visualization showing the value of national economic GDP changes, so that students can feel the prosperity of the country and the superiority of the socialist system more intuitively. High awakening: igniting the resonance of people's human nature bottom, suitable music can reach people's hearts directly, coordination and rational use of pictures become the most direct expression of emotion. In the explanation of editing technical knowledge of film and television audio, with the help of typical cases such as fighting against epidemic situation, the emotional awakening of strengthening ideals and beliefs and building a Chinese dream together is carried out. For example, the most beautiful nurse went retrograde during the anti-epidemic period, and the picture of Chinese medical team saving one country by one province was accompanied by a song "Youth". The resolute face of the medical team members and the passionate lyrics of "Don't stop your steps because of hardships" fully express the beautiful vision of the Chinese people at that time, "I hope to return to be still that teenager", and it is also a direct exposition of the socialist core values.

\subsection{Ideological and Political Assessment}

The evaluation system of Short Video Creation course includes ideological and political elements, including students' awareness of socialist core values, social responsibility, solidarity and cooperation, etc. The combination of process assessment and final assessment is adopted to reduce the proportion of professional knowledge and skills assessment to $80 \%$ and increase the ideological and political assessment of the course by $20 \%$. Evaluation adds process evaluation, including multi-dimensional evaluation criteria such as teacher comments, students' mutual evaluation and the number of platform praises of short video works, so as to objectively and comprehensively evaluate students' learning process. Encourage the development of group activities in various forms, such as learning sentiment report and learning achievement display, focusing on assessing students' professional knowledge, whether to form creative thinking with socialist core values and establish correct values.

\section{CONCLUSION}

The ideological and political construction of "Short Video Creation" course combines explicit creative thinking with media production technology learning with implicit ideological and political education, integrates socialist core values into classroom teaching quietly, and helps students form creative thinking based on core values. Train more and more creators to become producers of high praise rate videos and disseminators of positive energy, and promote the virtuous circle development of short video industry. Present highquality short video content with more valuable identification, emotional resonance and rich connotation for the broad masses of the people, so as to meet the spiritual needs of the people.

\section{REFERENCES}

[1] Jie Zhou, 2021 Research Report on China's network audio-visual development, China Network audio-visual program service association,2021,pp.03-05.

[2] 2020 tiktok data report, Beijing byte jumping Technology Co., Ltd. 2021, pp. 07-08.

[3] Gibbs, Colin. Short-form may be long-tail for mobile video. RCR Wireless News,2007, 14(1):115-128.

[4] Yu Shu, short video: a sharp tool to carry forward the theme, News Front, 2018 (03), pp. 24-28.

[5] Jinling Zhang, How can mainstream media tiktok short video to transmit positive energy, Media, 2019 (07), pp. 15-18.

[6] Yuting Luo, Yongtu Li, Shake out positive energy: application of shaking in college students' Ideological and political education, Ideological And Theoretical Education, 2019 (03), pp. 83-89.

[7] 2020 tiktok data report, Beijing byte jumping Technology Co., Ltd., 2021, pp. 08-09. 